\title{
Radiochemical analysis of concrete samples from accelerator
}

\section{waste}

\section{Journal Article}

\section{Author(s):}

Schumann, Dorothea; Kiselev, Daniela; Teichmann, Sabine; Synal, Hans-Arno; Kubik, Peter

Publication date:

2012-11

Permanent link:

https://doi.org/10.3929/ethz-b-000058765

Rights / license:

In Copyright - Non-Commercial Use Permitted

Originally published in:

Radiochimica acta 100(11), https://doi.org/10.1524/ract.2012.1976 


\title{
Radiochemical analysis of concrete samples from accelerator waste
}

\author{
By D. Schumann ${ }^{1, *}$, D. Kiselev ${ }^{1}$, S. Teichmann ${ }^{1}$, H.-A. Synal ${ }^{2}$ and P. Kubik ${ }^{2}$ \\ ${ }^{1}$ Paul Scherrer Institute Villigen, 5232 Villigen PSI, Switzerland \\ 2 ETH Zurich, Institute of Particle Physics, Schafmattstrasse 20, 8093 Zurich, Switzerland
}

(Received July 25, 2011; accepted in revised form March 6, 2012)

(Published online October 8, 2012)

\section{Accelerator waste / Concrete, radiochemical analytics / Long-lived radionuclides}

\begin{abstract}
Summary. For the decommissioning and disposal of shielding concrete from accelerator facilities, the Swiss Authorities require information on the radionuclide inventory. Besides the easy-to-measure $\gamma$-emitters ${ }^{152} \mathrm{Eu},{ }^{60} \mathrm{Co},{ }^{44} \mathrm{Sc},{ }^{133} \mathrm{Ba},{ }^{154} \mathrm{Eu}$, ${ }^{134} \mathrm{Cs},{ }^{144} \mathrm{Ce},{ }^{22} \mathrm{Na}$, also long-lived radionuclides emitting $\alpha$ or $\beta$-radiation like ${ }^{129} \mathrm{I},{ }^{10} \mathrm{Be},{ }^{36} \mathrm{Cl},{ }^{239 / 240} \mathrm{Pu}$ and ${ }^{238} \mathrm{U}$ have to be studied in order to obtain an overview to which extent they are produced and whether they represent a safety issue. In this study, we present the chemical separation and determination of selected radionuclides in shielding concrete from two different positions in the accelerator facilities at the Paul Scherrer Institute (PSI), the BX2 station, which was shut down in 1998, and the environment of the target M station, where the samples were taken in 1985 during reconstruction. The results of the measurements show that in no case the radionuclide content represents a safety risk. The components can be decommissioned corresponding to the Swiss safety regulations.
\end{abstract}

\section{Introduction}

Activated components from accelerator facilities, foreseen for an intermediate or final disposal, have to be characterized concerning their radionuclide inventory, as required by the responsible Swiss authorities (NAGRA - Nationale Genossenschaft für die Lagerung radioaktiver Abfälle). Theoretical predictions [1] help to give an estimate, but radiochemical analyses are often necessary to benchmark the results. Besides metallic material (mainly steel and aluminum), also the concrete shielding in the surrounding area of particle accelerators becomes activated, as indicated by dose rate measurements. Therefore, an experimental examination, at least for some selected representative samples, is required. For PSI, that is operating the world-wide most powerful proton accelerator with up to $2.3 \mathrm{~mA}$ beam current and a beam energy of $590 \mathrm{MeV}$, it is mandatory to provide accurate data on the radionuclide inventory of its accelerator waste. While metallic components like stainless steel, cast iron, copper, aluminum and others are relatively frequently analyzed and evaluated [2,3], only one attempt was started some years ago to characterize a first set of con-

\footnotetext{
*Author for correspondence (E-mail: dorothea.schumann@psi.ch).
}

crete samples, taken from the shielding of the BX2 target and beam dump [4]. This station was used as a logging target for the $72 \mathrm{MeV}$ beam of the Injector II cyclotron feeding the $590 \mathrm{MeV}$ ring cyclotron. The measurements included an snapshot $\gamma$-measurement of one selected sample; detailed investigations were only carried out concerning the content of $\mathrm{U}$ and $\mathrm{Pu}$ isotopes. As the main result of this study, it was pointed out that a) none of the $\gamma$-emitters detected in the samples are safety-relevant, b) the content of ${ }^{238} \mathrm{U}$ and ${ }^{239+240} \mathrm{Pu}$ exceeds the exemption limit for activated material of the Swiss Radiation Protection Act of 1994 for the innermost samples, but does not represent a high hazardous potential for final disposal and c) calculations are in fair agreement with the experimental data. However, long-lived $\beta$-emitters being potentially safety-relevant were not considered in this first work. Therefore, in the present report, we conducted a more extended study of concrete samples from the PSI accelerator facility including $\gamma$ - and $\alpha$-measurements, as well as accelerator mass spectrometry (AMS) for determining the long-lived radionuclides ${ }^{10} \mathrm{Be}$, ${ }^{36} \mathrm{Cl}$ and ${ }^{129} \mathrm{I}$ as examples. For some selected samples and isotopes, the data set reported in [4] is retrofitted.

For the licensing of decommissioning and disposal, longlived radionuclides are of special interest. Most of them become measurable only after elaborate chemical treatment. Besides attempts at other institutes to analyze accelerator waste (see for instance $[5,6]$ ), also chemical separation procedures have been developed for the determination of such radionuclides from waste components of nuclear power plants or other research facilities. In particular, where nuclear reactors had to be shut down and decommissioned, like for instance in the Nordic countries, the accompanying radioanalytics has been developed. So, to mention one example, at Ris $\varnothing$ National Laboratory for Sustainable Energy (Denmark) an extended radiochemical analysis system for nuclear waste management in decommissioning is available [7-11]. Some of the chemical separation techniques developed there can be adopted for our present task [12].

\section{Experimental}

\subsection{Sample taking and prearrangement}

The concrete samples called "E" were taken from the floor below the former Target M, a rotating graphite wheel, which 


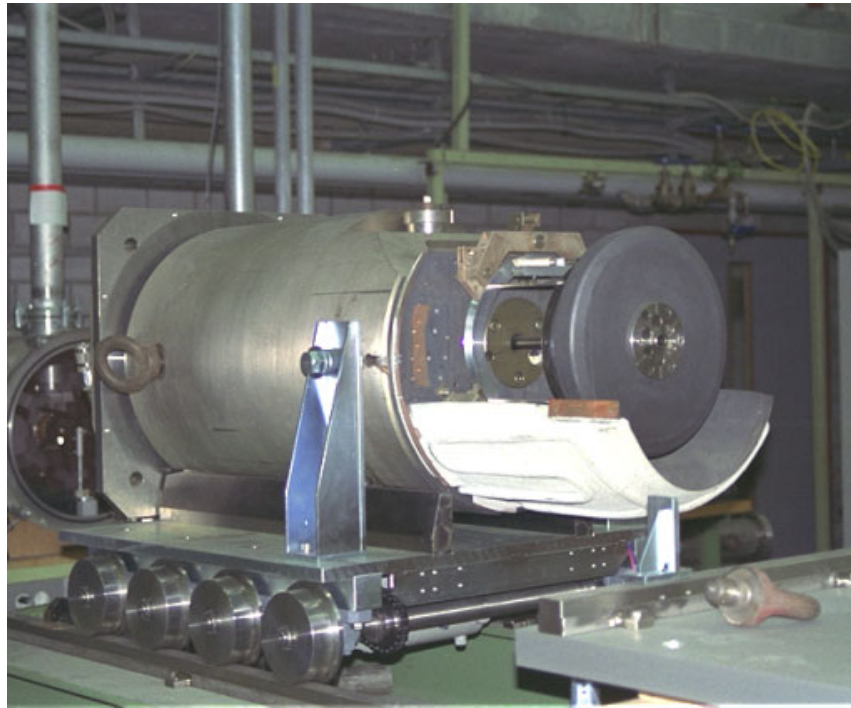

Fig. 1. Photograph of Target M mounted on the insert.

was hit by $590 \mathrm{MeV}$ protons for meson production. A photo of the target mounted on the insert is depicted in Fig. 1. The target itself was dismounted in 1985. The integrated beam current on the target was $10512 \mathrm{C}$.

In Fig. 2 a schematic view of the Target $M$ environment is shown. The target was positioned at $1.5 \mathrm{~m}$ above the floor level. The proton beam $\mathrm{P}$ hits the rotating target at an angle of $30^{\circ}$ at the point labeled Tg.M. Two beam lines, each at an angle of $22.5^{\circ}$, lead the produced mesons to the experimental areas, while the penetrating proton beam was transported to the next target station (Target "E", not visible in the figure). The floor below Target $\mathrm{M}$ consisted of concrete covered with a $60 \mathrm{~cm}$ thick iron plate for shielding. After removing the iron plate, our samples were taken both from the beam entrance side (1.10 m distance from Target $\mathrm{M})$ and exit $(3.44 \mathrm{~m}$ distance from Target $\mathrm{M}$ ) by performing two core drillings with diameters of $16 \mathrm{~cm}$, respectively. From each of the obtained two $50 \mathrm{~cm}$ long pillars 5 small equidistant samples were taken, as is illustrated in Fig. 3.

The second sample set named "B" stems from the vicinity of the former BX2 beamdump and was already partially
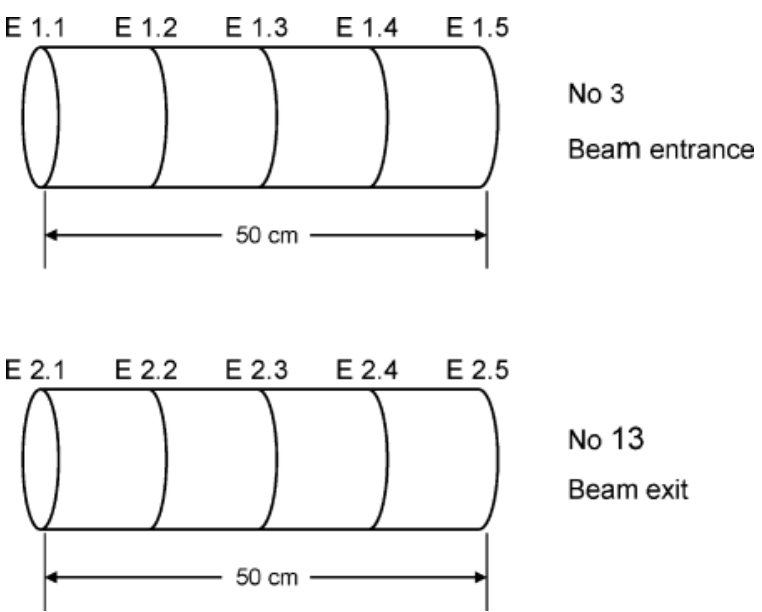

Fig. 3. Depiction of the two drilling cores and the positions of the sample taking.

studied in [4]. Figure 4 shows a schema of the beam dump and the sample taking positions. The BX2 target was in operation from 1984 till 1998 and was hit by an accumulated beam current of $6264 \mathrm{C}$. Details of the BM2 construction as well as the sample description are given in [4].

All samples were milled with a ball mill to a maximum grain size of $0.5 \mathrm{~mm}$, which was evaluated as sufficient for the chemical digestion of the concrete [13].

\subsection{Concrete composition}

The content of impurities within the material under study is essential for the estimation of the expected activation. Unfortunately, a detailed chemical analysis of the concrete composition before the construction of the equipment was not available. Therefore, one has to rely on estimated values. A typical concrete composition is shown in Table 1.

\subsection{Chemical treatment}

With the exception of the $\gamma$-measurement, which has been applied as a non-destructive measurement technique, all other methods used here require dissolution or at least par-

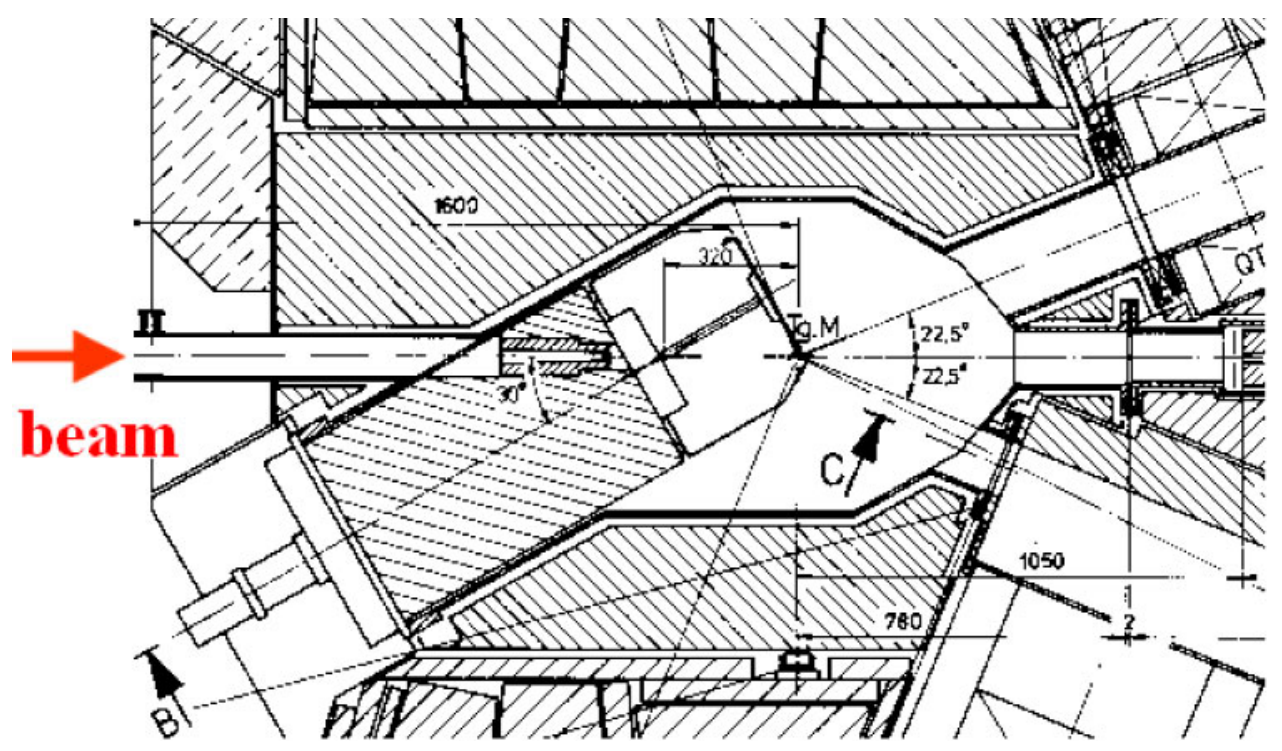

Fig. 2. Schematic view of the environment of Target $\mathrm{M}$. 


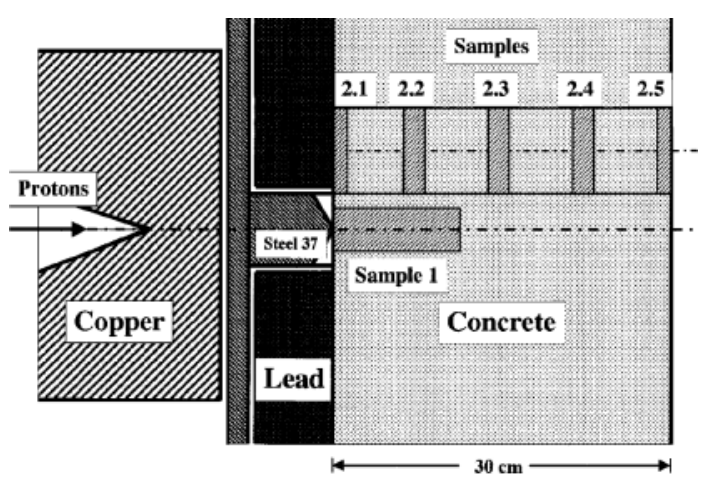

Fig. 4. Layout of the design of the BX2 beamdump (taken from [4]).

tial solution of the sample material. Which kind of sample decomposition can be applied depends on the radionuclides that have to be determined. Weinreich et al. [4] used for the uranium and plutonium determination a digestion procedure based on a mixture of concentrated HF and nitric acid, followed by a treatment with boric acid. The actinides are then additionally oxidized with $\mathrm{H}_{2} \mathrm{O}_{2}$ [4]. This method is very convenient and gives reliable and reproducible results, but is only applicable for elements that are not volatile during evaporation. Therefore, we could use this decomposition method for the determination of ${ }^{238} \mathrm{U}$ and ${ }^{239 / 240} \mathrm{Pu}$, but not for the volatile halogens ${ }^{36} \mathrm{Cl}$ and ${ }^{129} \mathrm{I}$. Hou et al. [12] used for the halogen determination a mixture of $\mathrm{HCl}$ and $\mathrm{HNO}_{3}$ in a closed system, however, this is only possible for samples with high ${ }^{36} \mathrm{Cl}$ content, where Liquid Scintillation Counting (LSC) can be applied as measuring technique [12] and addition of stable $\mathrm{Cl}$ is not necessary. For our samples, where a relatively low ${ }^{36} \mathrm{Cl}$ content had been expected, AMS is the only suitable technique. This method measures the ${ }^{36} \mathrm{Cl}$ content relative to an added stable carrier (isotopic ratio), and chlorine coming into the system from the digestion solution makes the measurement impossible due to the dilution of the final sample with stable chlorine. Therefore we had to look for a chlorine-free solution for the decomposition. The method of choice in this case is the so-called "Hot-water-digestion", which was successfully applied for the determination of the chlorine content in concrete [13]. Round-robin tests showed that the method is very reliable and the data are reproducible with an error of approximately $8-13 \%$. Summarizing these considerations, we arrived at the

Table 1. Typical composition of normal concrete (in ppm).

\begin{tabular}{lrlrlr}
\hline $\mathrm{O}$ & 500000 & $\mathrm{~N}$ & 120 & $\mathrm{Sm}$ & 4 \\
$\mathrm{Ca}$ & 210000 & $\mathrm{Cl}$ & $\leq 100$ & $\mathrm{Eu}$ & 3 \\
$\mathrm{Si}$ & 170000 & $\mathrm{Cr}$ & 70 & $\mathrm{Dy}$ & 2 \\
$\mathrm{Al}$ & 15000 & $\mathrm{Zn}$ & 50 & $\mathrm{Bi}$ & $<2$ \\
$\mathrm{H}$ & 10000 & $\mathrm{Zr}$ & 40 & $\mathrm{U}$ & 1.5 \\
$\mathrm{Fe}$ & 10000 & $\mathrm{~Pb}$ & 40 & $\mathrm{Yb}$ & 1.5 \\
$\mathrm{~K}$ & 6500 & $\mathrm{~V}$ & 30 & $\mathrm{Be}$ & 1 \\
$\mathrm{~S}$ & 6000 & $\mathrm{Ni}$ & 20 & $\mathrm{Co}$ & 1 \\
$\mathrm{Sb}$ & 6000 & $\mathrm{Cu}$ & 20 & $\mathrm{Ho}$ & 1 \\
$\mathrm{Mg}$ & 4500 & $\mathrm{Li}$ & 16 & $\mathrm{Tl}$ & $\leq 1$ \\
$\mathrm{Na}$ & 3500 & $\mathrm{Ce}$ & $\leq 12$ & $\mathrm{Th}$ & $\leq 1$ \\
$\mathrm{C}$ & 2500 & $\mathrm{Sn}$ & 10 & $\mathrm{~W}$ & $<1$ \\
$\mathrm{Ti}$ & 900 & $\mathrm{Rb}$ & 10 & $\mathrm{Cs}$ & $<1$ \\
$\mathrm{Mn}$ & 400 & $\mathrm{Gd}$ & 7 & $\mathrm{Ag}$ & $<1$ \\
$\mathrm{P}$ & 290 & $\mathrm{As}$ & 6 & $\mathrm{Hg}$ & 0.05 \\
$\mathrm{Ba}$ & 250 & $\mathrm{Ir}$ & $\leq 5$ & & \\
\hline
\end{tabular}

following treatment procedures for the determination of the desired isotopes:

${ }^{238} \mathbf{U},{ }^{239 / 240} \mathbf{P u}$ : An identical procedure as described in [4] was applied including the separation of the actinides by using ion exchange with BioRad and UTEVA columns and the sample preparation for the $\alpha$-measurement [14].

${ }^{10}$ Be: After adding $2 \mathrm{mg}$ of stable Be carrier, decomposition with aqua regia was used as described in [12]. Finally, the solution was evaporated to dryness and the residue dissolved in $1 \mathrm{M} \mathrm{HNO}_{3}$. This solution was fed onto a cation exchange column (DOWEX50x8, 200-400 mesh, $\mathrm{H}^{+}$form). The column was washed with $20 \mathrm{ml} 1 \mathrm{M} \mathrm{HNO}_{3}$ in order to remove traces of the isobaric ${ }^{10} \mathrm{~B}$, which can disturb the ${ }^{10} \mathrm{Be}$ AMS measurement. After that, Be can be removed with $1.1 \mathrm{M} \mathrm{HCl}$. The hydroxide was precipitated with ammonia solution, washed with bi-distilled water and filtered. After glowing at $900{ }^{\circ} \mathrm{C}$ the samples are ready for the AMS measurement.

${ }^{36} \mathrm{Cl}$ and ${ }^{129} \mathrm{I}$ : Because chlorine-containing acids cannot be used for the decomposition, the above described hotwater-digestion was applied in a slight modification: Instead of water, $1 \mathrm{M} \mathrm{HNO}_{3}$ was used for the digestion. Sample masses of about one $1 \mathrm{~g}$ were boiled together with $10 \mathrm{mg}$ of stable chlorine (natural) and iodine carrier (Woodward-Iodine) and $20 \mathrm{ml}$ acid solution in a tight three-neck vessel under a nitrogen flow which transports the volatiles into the corresponding adsorption vessels, as described in [1]. The stable carriers both have isotopic ratios lower than $10^{-14}$ concerning the content of ${ }^{36} \mathrm{Cl}$ and ${ }^{129} \mathrm{I}$, respectively. The halogens are precipitated with $\mathrm{AgNO}_{3}$. After washing, re-precipitation and drying, the samples were ready for AMS measurement.

\subsection{Measurement techniques}

$\gamma$-measurements were carried out with a high-purity coaxial germanium detector (PGT; $18.7 \%$ relative efficiency) using the GENIE2000 software from CANBERRA.

Accelerator mass spectrometry measurements were performed at ETH Zurich, Switzerland (6 MV van-de-Graaff EN tandem accelerator at the ETH Laboratory of Ion Beam Physics). Details of the measurement technique as well as the used standard and half-life for ${ }^{10} \mathrm{Be}$ are described in [15].

After electro-deposition of $\mathrm{U}$ and Pu from $\mathrm{H}_{2} \mathrm{SO}_{4} / \mathrm{NaHSO}_{4}$ buffer solutions on stainless steel disks, $\alpha$-measurements were carried out with OCTETE PC equipment using silicon detectors with an efficiency of $35 \%$. For detailed description of the $\alpha$-measurements see $[4,14]$.

\subsection{Uncertainties of the measurements}

For the $\alpha$-measurements of plutonium a systematic uncertainty of $25-40 \%$ had to be assumed. This was caused by variations in the chemical yield during separation. The ${ }^{238} \mathrm{U}$ separation worked generally better, with chemical yields of better than $95 \%$. Measurement uncertainties were between 4 and $6 \%$. However, inhomogeneity in the samples has to be expected.

The uncertainty of the $\gamma$-measurements is dominated by the quality of the calibration source. We used a ${ }^{152} \mathrm{Eu}$ source 
from Amersham/Buchler with a certified uncertainty of $5 \%$. Self-shielding can be neglected since the samples are small and were measured in a distance of at least $5 \mathrm{~cm}$ from the detector surface.

AMS measurements are independent of the chemical yield, since the isotopic ratio radionuclide relative to a stable isotope) is measured. The original content of stable isotopes of the elements of interest in the concrete is in the range of $1 \%$ as the highest (for chlorine $100 \mathrm{ppm}$, for beryllium $1 \mathrm{ppm}$, for iodine lower than $0.05 \mathrm{ppm}, \mathrm{s}$. Table 1), and therefore does not contribute to the overall uncertainty. If the ratios are high enough and the samples are preferably free of isobaric contaminants, measurement uncertainties of a few percent can be reached. Unfortunately, our samples were not absolutely free of contaminations, and, therefore, showed low statistics during the AMS measurement. Because of that, the average uncertainties were $20 \%$ for ${ }^{10} \mathrm{Be}$ and ${ }^{36} \mathrm{Cl}$ and $5 \%$ for ${ }^{129} \mathrm{I}$. For ${ }^{36} \mathrm{Cl}$, we have additionally to consider the efficiency of the leaching process, which amounts to $95 \%$ with $8 \%$ uncertainty in average [12]. Therefore, we obtained an average uncertainty for this isotope of $25 \%$.

\section{Results, discussion and evaluation}

For explaining the residue nuclide production in the described shielding material, a broad spectrum of nuclear reactions has to be considered. Besides the primer interaction of the protons with a big variety of elements present in the concrete also the induced neutrons as well as other secondary particles undergo reactions with the target material. Depending on the cross sections, also low-amounting impurities can have an impact on the final radionuclide inventory. Besides compound nucleus reactions, also spalla- tion and fission reactions - especially in the case of the E samples - have to be considered induced both by protons and high-energetic neutrons. Moreover, different production rates and reaction channels for neutron capture have to be expected with a changing neutron spectrum. Therefore, the radionuclide inventory does not necessarily depend linearly only on the distance of the sample taking position from the radiation source. The large amount of parameters influencing the production rates makes the interpretation of the experimental results and especially the explanation using nuclear reaction models very difficult. Nevertheless, some qualitative conclusions can be drawn.

In Table 2 , the results of the $\gamma$-measurements are summarized. For comparison, the values published in [4] for the sample 1 of the BX2 target, which is located in about $14 \mathrm{~cm}$ away from the beam entrance in beam direction, is given. Considering the proton beam energy of $72 \mathrm{MeV}$, with a range in copper of less than $8 \mathrm{~mm}$, it is expected, that the radionuclide production in the concrete shielding was mainly induced by secondary neutrons and not by protons penetrating the steel and lead shielding. This is confirmed by the fact that sample 1, which is located on the beam axis, shows similar values as samples 2.2.1 and 2.2.2, which are located farer away from the beam axis. With increasing depth, corresponding to a decreasing neutron field, the specific activities become lower, which is clearly visible for all measured radionuclides. Sample B2.2.2 shows in most of the cases a higher activity than B2.2.1, because B2.2.1 is located directly behind the lead shielding, changing the parameters of the induced neutron field.

In Table 3, the results of the AMS $\left({ }^{129} \mathrm{I},{ }^{10} \mathrm{Be},{ }^{36} \mathrm{Cl}\right)$ - and $\alpha\left({ }^{239-240} \mathrm{Pu},{ }^{238} \mathrm{U}\right)$-measurements are shown. For comparison, the data for uranium and plutonium already published

Table 2. $\gamma$-spectrometric measurements of all concrete samples (calibrated to May/2003, with exception of sample 1: July/2003).

\begin{tabular}{|c|c|c|c|c|c|c|c|c|}
\hline Sample & ${ }^{152} \mathrm{Eu}$ & ${ }^{60} \mathrm{Co}$ & ${ }^{44} \mathrm{Ti} /{ }^{44} \mathrm{Sc}$ & ${ }^{133} \mathrm{Ba}$ & ${ }^{154} \mathrm{Eu}$ & ${ }^{134} \mathrm{Cs}$ & ${ }^{144} \mathrm{Ce}$ & ${ }^{22} \mathrm{Na}$ \\
\hline Half-life (y) & 13.537 & 5.2714 & 58.9 & 10.51 & 8.593 & 2.0648 & 0.23257 & 2.6019 \\
\hline $\begin{array}{l}\text { Exemption } \\
\text { limit }(\mathrm{Bq} / \mathrm{g})\end{array}$ & $\begin{array}{c}7 \\
(\mathrm{~Bq} / \mathrm{g})\end{array}$ & $\begin{array}{c}1 \\
(\mathrm{~Bq} / \mathrm{g})\end{array}$ & $\begin{array}{c}2 \\
(\mathrm{~Bq} / \mathrm{g})\end{array}$ & $\begin{array}{c}10 \\
(\mathrm{~Bq} / \mathrm{g})\end{array}$ & $\begin{array}{c}5 \\
(\mathrm{~Bq} / \mathrm{g})\end{array}$ & $\begin{array}{c}0.5 \\
(\mathrm{~Bq} / \mathrm{g})\end{array}$ & $\begin{array}{c}2 \\
(\mathrm{~Bq} / \mathrm{g})\end{array}$ & $\begin{array}{c}3 \\
(\mathrm{~Bq} / \mathrm{g})\end{array}$ \\
\hline E1.1 & 8.18 & 2.04 & 0.09 & 0.13 & & & & \\
\hline E1.2 & 4.61 & 0.81 & 0.22 & & & & & \\
\hline E1.3 & 4.74 & 1.02 & 0.37 & & & & & \\
\hline E1.4 & 0.765 & 0.51 & 0.27 & & & & & \\
\hline E1.5 & 0.278 & 0.49 & 0.24 & & & & & \\
\hline E2.1 & 5.92 & 1.12 & & & & & & 0.73 \\
\hline E2.2 & 6.78 & 1.15 & 0.12 & & & & & \\
\hline E2.3 & 3.18 & 0.75 & & & & & & 0.26 \\
\hline E2.4 & 1.36 & 0.60 & 0.31 & & & & & \\
\hline E2.5 & 0.73 & 0.32 & 0.23 & & & & & \\
\hline Sample 1 & $2616^{a}$ & $586^{a}$ & & $15^{a}$ & $305^{a}$ & $229^{a}$ & & $290^{a}$ \\
\hline B2.2.1 & 2646 & 712 & & 18.2 & 320.6 & 156.3 & 84.3 & \\
\hline B2.2.2 & 2949 & 1421 & & 27.3 & 302.5 & 167.9 & & \\
\hline B2.2.3 & 1676 & 508 & & 11.5 & 160.0 & 80.5 & & \\
\hline B2.2.4 & 987 & 247 & & 4.21 & 88.0 & 51.7 & & \\
\hline B2.2.5 & 866 & 243 & & 4.12 & 73.7 & 47.9 & & \\
\hline
\end{tabular}

a: values taken from [4] 
Table 3. Results of the AMS- and $\alpha$-measurements

\begin{tabular}{|c|c|c|c|c|c|}
\hline Sample & ${ }^{129} \mathrm{I}$ & ${ }^{10} \mathrm{Be}$ & ${ }^{36} \mathrm{Cl}$ & ${ }^{239 / 240} \mathrm{Pu}$ & ${ }^{238} \mathrm{U}$ \\
\hline Half-life (y) & $1.57 \times 10^{7}$ & $1.51 \times 10^{6}$ & $3.01 \times 10^{5}$ & $24110 / 6563$ & $4.468 \times 10^{9}$ \\
\hline $\begin{array}{l}\text { Exemption } \\
\text { limit }(\mathrm{Bq} / \mathrm{g})\end{array}$ & $\begin{array}{c}0.09 \\
(\mathrm{~Bq} / \mathrm{g})\end{array}$ & $\begin{array}{c}9 \\
(\mathrm{~Bq} / \mathrm{g})\end{array}$ & $\begin{array}{c}1000 \\
(\mathrm{~Bq} / \mathrm{g})\end{array}$ & $\begin{array}{c}0.04 \\
(\mathrm{~Bq} / \mathrm{g})\end{array}$ & $\begin{array}{c}0.2 \\
(\mathrm{~Bq} / \mathrm{g})\end{array}$ \\
\hline $\mathrm{E} 1.1$ & $6.2 \times 10^{-4}$ & & 82 & 0.347 & 12.72 \\
\hline $\mathrm{E} 1.2$ & $4.3 \times 10^{-4}$ & $4.0 \times 10^{-3}$ & - & & \\
\hline $\mathrm{E} 1.3$ & $9.1 \times 10^{-4}$ & $1.0 \times 10^{-3}$ & 10 & & \\
\hline E1.4 & $7.0 \times 10^{-4}$ & $1.2 \times 10^{-3}$ & 0.4 & & \\
\hline $\mathrm{E} 1.5$ & $8.2 \times 10^{-4}$ & $5.1 \times 10^{-3}$ & 0.3 & 0.071 & 13.10 \\
\hline E2.1 & $6.2 \times 10^{-4}$ & $8.4 \times 10^{-2}$ & 34.6 & 0.286 & 11.28 \\
\hline E2.2 & $3.1 \times 10^{-4}$ & $8.5 \times 10^{-2}$ & 64.3 & & \\
\hline E2.3 & $3.2 \times 10^{-4}$ & $4.1 \times 10^{-2}$ & 32.5 & & \\
\hline E2.4 & $7.2 \times 10^{-4}$ & $3.3 \times 10^{-2}$ & 13.2 & & \\
\hline E2.5 & $3.5 \times 10^{-4}$ & & 5.7 & 0.028 & 13.95 \\
\hline Sample 1 & $1.2 \times 10^{-3}$ & $9.6 \times 10^{-1}$ & - & & \\
\hline B2.2.1 & $2.0 \times 10^{-2}$ & 2.9 & - & $32.4^{a}$ & $13.1^{a}$ \\
\hline B2.2.2 & $2.4 \times 10^{-2}$ & 1.5 & 6148 & $30.7^{a}$ & $14.7^{a}$ \\
\hline B2.2.3 & $4.3 \times 10^{-2}$ & $7.0 \times 10^{-1}$ & - & $11.9^{a}$ & $8.2^{a}$ \\
\hline B2.2.4 & $2.8 \times 10^{-2}$ & $4.8 \times 10^{-1}$ & - & $12.3^{a}$ & $12.9^{a}$ \\
\hline B2.2.5 & $5.5 \times 10^{-2}$ & $3.0 \times 10^{-1}$ & - & $5.66^{a}$ & $14.7^{a}$ \\
\hline 0 & & & & $<0.18^{a}$ & $8.24^{a}$ \\
\hline
\end{tabular}

a: values taken from [4] for comparison

in [4] are displayed as well as a sample called "0", which represents a model analysis for the $\mathrm{U}$ and $\mathrm{Pu}$ content in non-irradiated concrete. The detection limit for the Pu determination is $0.01 \mathrm{mBq}$.

First, it can be seen from the results in both tables that the samples from the BX2 target have generally much higher radionuclide inventories than the samples from the target $M$ floor, although the received beam dose of target $M$ is a factor 1.7 higher. From the beam dose alone, comparable values should be expected, but we find differences of several orders of magnitude in some cases. The following issues explain the differences:

- Distance of the samples from the target

- E-samples have a distance from the target of $1.5 \mathrm{~m}$ from the floor $+1.1 \mathrm{~m}$ or $3.4 \mathrm{~m}$, respectively, from the target plus $60 \mathrm{~cm}$ iron shielding for the nearest $(\mathrm{E} 1.1$ and E2.1.)

- B-samples have a distance from the target of $14 \mathrm{~cm}$ for the nearest (sample 1).

- Shielding

- E-samples are shielded with $60 \mathrm{~cm}$ iron

- B-samples are shielded by around $7 \mathrm{~cm}$ iron (sample 1) or lead (all other samples)

- Design and material of target

- BX2 is a compact thick copper target, where the $72 \mathrm{MeV}$ proton beam is completely stopped. A high production rate of secondary particles has to be expected.

- Target $\mathrm{M}$ is a $0.5 \mathrm{~cm}$ thick rotating carbon wheel. Most $590 \mathrm{MeV}$ protons penetrate the material; only a few percent interact with carbon to produce mesons and secondary neutrons (the beam is further transported to a second graphite target for myon production).
- Carbon with a low atomic number is less efficient for neutron production in comparison to copper.

Secondly, generally most of the values are decreasing with increasing depth of the sample taking positions, which corresponds to the decreasing high-energetic neutron field. The E-samples taken at the beam entrance side (E1.1-E1.5) tend to show lower values for the radionuclides ${ }^{10} \mathrm{Be}$ and ${ }^{36} \mathrm{Cl}$ than the samples behind the target. This seems to be logical, because more neutrons are produced in the beam direction. This tendency is not seen for ${ }^{129} \mathrm{I}$ and the $\gamma$-emitters. An interpretation is difficult at the moment, since the detailed particle spectra at the sample positions are not known.

Some of the obtained values shall be discussed in detail.

${ }^{238} \mathrm{U}$ and ${ }^{239 / 240} \mathrm{Pu}$ : Uranium is a component in normal concrete. We find a more or less constant value in all samples (average $12.7 \pm 2.0 \mathrm{mBq} / \mathrm{g}$, corresponding to around $1-1.5 \mathrm{ppm}$ given in the literature [16]). The plutonium is produced in nuclear reactions with secondary neutrons. In [4], it was concluded that the content of the B-samples exceeds the limits given in the Swiss radiation Protection Act of $1994(20 \mathrm{mBq} / \mathrm{g})$ for the innermost samples. However, in the updated version of 2009, this limit is given as $40 \mathrm{mBq} / \mathrm{g}$, which is not exceeded by any of the samples. The newly measured E-samples have generally very low $\mathrm{Pu}$ content (far below the exemption limits); the lowest are near the detection limit of $0.01 \mathrm{mBq} / \mathrm{g}$.

${ }^{129} \mathrm{I}$ and ${ }^{10} \mathrm{Be}$ : With a few exceptions, all values are lower than $1 \mathrm{mBq} / \mathrm{g}$. No sample requires any consideration for safety measures regarding intermediate or final disposal. While the production of ${ }^{129} \mathrm{I}$ can be neglected completely, some activation of impurities by neutrons took place for $\mathrm{Be}$ in the samples stemming from the BX2. The beryllium content is only about $1 \mathrm{ppm}$, but the cross-section of the direct neutron activation ${ }^{9} \mathrm{Be}(n, \gamma){ }^{10} \mathrm{Be}$ is obviously high enough to produce amounts in nearly the same 
order of magnitude. To some extend, also spallation on oxygen might cause ${ }^{10} \mathrm{Be}$ production, although the contribution is probably low due to the low proton energy of $71 \mathrm{MeV}$. Corresponding works to predict these values by using calculation codes are currently ongoing.

${ }^{36} \mathrm{Cl}$ : Although only around $100 \mathrm{ppm}$ of chlorine are present in concrete, the neutron capture cross section of ${ }^{35} \mathrm{Cl}$ is so high, that considerable amounts of ${ }^{36} \mathrm{Cl}$ were produced even in the E-samples. For the B-samples, the expected isotopic ratios were too high for an AMS measurement. Therefore, we investigated only one sample by this method by diluting the material with a factor of $10^{3}$. However, using Liquid Scintillation Counting (LSC) as recommended in [11] would be the better choice for such highly concentrated samples, also allowing for application of another digestion method. Nevertheless, the obtained value for B2.2.2 of $6 \mathrm{~Bq} / \mathrm{g}$ gives us the opportunity to evaluate its importance for decommissioning of the concrete components. Since the exemption limit is not exceeded, the ${ }^{36} \mathrm{Cl}$ content does not represent a safety risk.

\section{Outlook}

For our future work, we intend to apply the existing calculation programs to the concrete samples and compare the calculational predictions with the experimental values, as was already done in [4] for uranium and plutonium. Furthermore, other components of the radionuclide inventory like ${ }^{3} \mathrm{H},{ }^{14} \mathrm{C}$ and ${ }^{41} \mathrm{Ca}$ should be taken into consideration.

Acknowledgment. We would like to thank R. Weinreich and S. Bajo for carrying out the $\gamma$-and $\alpha$-measurements.

\section{References}

1. Schumann, D., Neuhausen, J. Weinreich, R., Atchison, F., Kubik, P., Synal, H.-A., Korschinek, G., Faestermann, Th., Rugel, G.: Determination of the radionuclide inventory in accelerator waste using calculation and radiochemical analysis. NIM B 264, 83 (2007).

2. Kiselev, D., Schumann, D., Teichmann, S., Wohlmuther, M.: Activation of Targets and Accelerator Components at PSI - a Comparison of Simulation and Measurement, 42nd ICFA Advanced Beam Dynamics Workshop on High-Intensity, HighBrightness Hadron Beams, Nashville, USA, 25-29 August 2008, http://snsapp1.sns.ornl.gov/pls/hb08/toc.htm.

3. Schumann, D., Wohlmuther, M., Kubik, P., Synal, H.-A., Alfimov, V., Korschinek, G., Rugel, G., Festermann, T.: Radiochemical analytics of a copper beam dump irradiated with highenergetic protons. Radiochim. Acta 97, 123 (2009).

4. Weinreich, R., Bajo, S., Eikenberg, J., Atchison, F.: Determination of uranium and plutonium in shielding concrete. J. Radioanal. Nucl. Chem. 261, 319 (2004).

5. Hoeppener-Kramar, U., Pimpl, M., Willmann, F.: Application procedures for low-level radionuclide analysis in environmental monitoring for the purpose of clearance measurements of materials from decommissioning of nuclear facilities. J. Radioanal. Nucl. Chem. 226, 99 (1997).

6. Bessho, K. Matsumura, H., Miura, T. Wang, Q., Masumoto, K. Matsuhiro, T., Nagashima, Y., Seki, R., Takahashi, T., Sasa, K., Sueki, K.: AMS analysis of ${ }^{36} \mathrm{Cl}$ induced in concrete of accelerator facilities. Radiochim. Acta 94, 801 (2006).

7. Hou, X. L.: Rapid analysis of ${ }^{14} \mathrm{C}$ and ${ }^{3} \mathrm{H}$ in graphite and concrete for decommissioning of nuclear reactor. Appl. Radiat. Isot. 62, 871 (2005).

8. Hou, X. L., Østergaard, L. F., Nielsen, S. P.: Determination of ${ }^{63} \mathrm{Ni}$ and ${ }^{55} \mathrm{Fe}$ in nuclear waste samples using radiochemical separation and liquid scintillation counting. Anal. Chim. Acta 535, 297 (2005).

9. Hou, X. L.: Radiochemical determination of ${ }^{41} \mathrm{Ca}$ in nuclear reactor concrete. Radiochim. Acta 93, 611 (2005).

10. Hou, X. L.: Radiochemical analysis of radionuclides difficult to measure for waste characterization in decommissioning of nuclear facilities. J. Radioanal. Nucl. Chem 273, 43 (2007).

11. Hou, X., Roos, P.: Critical comparison of radiometric and mass spectrometric methods for the determination of radionuclides in environmental, biological and nuclear waste samples. Anal. Chim. Acta 608, 105 (2008)

12. Hou, X.: Radiochemical Analysis for Nuclear Waste Management in Decommissioning. NKS-B RadWaste report, July 2010 (ISBN 978-87-7893-292-1).

13. http://www.tfb.ch/htdocs/Files/VSS/VSS546d.pdf (Heisswasseraufschluss).

14. Bajo, S., Eikenberg, J.: Electrodeposition of actinides for alphaspectrometry. J. Radioanal. Nucl. Chem. 242, 745 (1999).

15. Kubik, P. W., Christl, M.: ${ }^{10} \mathrm{Be}$ and ${ }^{26} \mathrm{Al}$ measurements at the Zurich 6 MV Tandem AMS facility. NIM B 268, 880 (2010).

16. Peehs, M., Walter, T., Walter, S.: Uranium, uranium alloys and uranium compounds. In: Ullmanns Encyclopedia of Industrial Chemistry. $5^{\text {th }}$ completely Revised Edition, Bol. A27, (Elvers, B., Hawkins, S., eds.), VCH Verlagsgesellschaft mbH, Weinheim (1996), p. 289. 